- The Retaining and Returning Advisory Service in postgraduate English deaneries provides educational, practical and pastoral support for dentists on a career break and those at risk of leaving the profession.

- Users' feedback was a clear endorsement of the service: they felt it was relevant to their needs, increased confidence and encouraged return to work.

- The workforce profile in dentistry is changing and the Retaining and Returning Advisers (RRAs) are well placed to respond to these circumstances. This paper offers a timely evaluation of the supportive role the service provides.

\title{
Supporting return to dentistry: a national evaluation of the Retaining and Returning Advisory Service
}

\author{
V. R. Firmstone, ${ }^{1}$ A. D. Bullock, ${ }^{2}$ J. Bedward ${ }^{3}$ and J. W. Frame ${ }^{4}$
}

Introduction Workforce concerns in National Health Service (NHS) dentistry have led to Government initiatives to strengthen recruitment and retention. This study (commissioned by the Department of Health, England) explored the role, uptake and user reaction to the new Retaining and Returning Advisory Service in dentistry operating in all 12 postgraduate deaneries in 2002. Method The primary focus of the evaluation study was the first year of the Retaining and Returning Advisory Service. All 12 Retaining and Returning Advisers (RRAs) were interviewed twice; all completed a record form for each one-to-one contact with users of the service $(n=217)$; and users' views were elicited through questionnaires $(n=82)$ and case study interviews $(n=10)$. Results RRAs' key activities in the first 12 months were to raise awareness of their role and provide one-to-one support for users $(n=217)$. Some also organised courses for dentists out of practice. Most oneto-one contacts were with female dentists on career breaks and registered on the Keeping in Touch Scheme (KITS). Support included: (i) planning continuing education; (ii) advice on job applications and requirements; and (iii) general careers guidance. Users' feedback was positive: confidence was increased and they valued targeted, hands-on courses. Postgraduate Dental Deans have integrated RRAs into their wider activities. Conclusion The Retaining and Returning Advisory Service provided support to potentially vulnerable groups of dentists. The joint launch of the Retaining and Returning Advisory Service, the revised Keeping in Touch Scheme, and expanded availability of update courses created a comprehensive package of support.

\section{INTRODUCTION}

Government commitment to improve access to National Health Service dentistry has led to a range of initiatives

\footnotetext{
Research Fellow; ${ }^{2}$ Reader in Medical and Dental Education: ${ }^{3}$ Research Fellow, Centre for Research in Medical and Dental Education (CRMDE), School of Education, University of Birmingham, Birmingham B15 2TT; ${ }^{4}$ Postgraduate Dental Dean, Dental Division, West Midlands Workforce Deanery, Birmingham Dental Hospital, St Chad's Queensway, Birmingham B4 6NN Correspondence to: Dr Vickie Firmstone Email:v.r.firmstone@bham.ac.uk
}

\section{Refereed Paper}

Accepted 2 November 2006

DOI: $10.1038 /$ bdj.2007.895

${ }^{\circledR}$ British Dental Journal 2007; 203: 413-417 aimed to strengthen recruitment and retention to the NHS dental service. ${ }^{1,2}$ Such workforce concerns are not unique to dentistry, ${ }^{3}$ for example, recruitment and retention strategies have also been established in the medical profession. ${ }^{4,5}$ This paper reports on an evaluation study of a specific initiative introduced for dentists in England - the Retaining and Returning Advisory Service, launched in 2002, following the publication of the Better opportunities for women dentists: a review of the contribution of women dentists to the workforce. ${ }^{6}$ Commissioned by the Department of Health (England), this large-scale national survey (4,500 responses) pro- vided empirical evidence to support the widely accepted view that dentists find it difficult to return to practice following a career break. Obstacles include: loss of confidence, loss of manual skills, working hours, childcare and emotional difficulties. ${ }^{7}$ More recently, the introduction of the General Dental Council's Lifelong Learning Scheme ${ }^{8}$ has meant that keeping up-to-date and participation in continuing professional development (CPD) has become an essential requirement of returning to practice.

A significant recommendation of the Better opportunities for women dentists report ${ }^{6}$ was the appointment of a new Retaining and Returning Adviser (RRA) 
for each postgraduate dental deanery, to support dentists' return to work following a career break. An evaluation of their effectiveness was proposed which should be planned in advance using an agreed protocol to achieve consistency across deaneries. Also suggested were revisions to the existing Keeping in Touch Scheme (KITS), and increased availability of update courses for returning dentists (Getting Back to Practice courses).

Financed nationally by the Department of Health (England), the contract for RRAs was established from early 2002 for two sessions per week (equivalent to one day) for a period of three years, renewable on an annual basis. Within a few months, two further RRAs were also established to work crossnationally with Dental Care Professionals (DCP RRAs). For the new KITS, the annual allowance increased to £350 used to retain registration on the dental register, and subscribe to a professional association, a peer reviewed dental journal and a professional indemnity society. ${ }^{9}$ In addition, KITS membership was extended to offer access to support from the local RRA, free continuing dental education courses, free distance learning material, and became accessible to dentists planning a break of less than one year.

The primary goals of this enhanced package of provision were to provide educational support and advice for dentists at risk of leaving the dental profession and to encourage dentists already taking a career break to return to practice.

This paper reports key findings from the national evaluation (funded by the Department of Health, England) of the new Retaining and Returning Advisory service, which was primarily undertaken in its first 12 months. A full report of the evaluation study is available. ${ }^{10}$

\section{DESIGN AND METHODS}

The purpose of the study was to explore the RRAs' core activities, service uptake, and users' reaction. The research was in three phases.

In Phase 1 (February-April 2002), semistructured interviews were undertaken with all RRAs ( $n=12)$; these were used to elicit expectations and plans for the new role. In Phase 2 (May-April 2003), the Retaining and Returning Advisory Service was monitored for 12 months using standardised records and feedback questionnaires to users. Records were self-completed by RRAs for every oneto-one contact with a service user $(\mathrm{n}=$ 217). RRAs then distributed feedback questionnaires to each user at the end of their (foreseeable) contact with the RRA and were prompted to record this on the standardised record form. Completed user questionnaires were returned direct to the research office using a pre-paid envelope ( $n=82$ ). To achieve consistency across deaneries, written guidance on the completion of standardised records and the distribution of feedback forms was provided by the evaluation team and face-to-face advice was also offered at national meetings of RRAs. In Phase 3 (April-September 2003), RRAs were interviewed again $(n=12)$. This sought their reflections on the development of the role, and suggestions for the future. Also in Phase 3 (July-September 2003), a sample of service users was interviewed $(n=10)$. These were selected by the RRAs and were intended as illustrative case studies of good practice. The interviews explored motivations for accessing the service, and views towards the RRA support provided.

For the purpose of qualitative data analysis, consent to tape-record all 34 interviews was secured and all were transcribed. Transcripts were scrutinised to identify main themes, manually coding the data by reading and noting emerging themes and highlighting relevant text. ${ }^{11}$ Quantitative data (closed response option and six-point rating scales), as well as qualitative data (textual comments from open questions) were integrated in the RRA records and user questionnaires. All records and questionnaires were input into MS Excel and quantitative data were analysed using SPSS.

This paper synthesises the main findings into five subheadings: key activities of the RRAs; service uptake; support provided; user feedback; and RRA reflections of the role.

\section{RESULTS}

\section{Key activities of the RRAs}

The RRAs' role during their first 12 months was wide ranging. Four principal activities were distilled: 1) awarenessraising of the new service; 2) advising and supporting individuals on a one-toone basis; 3) organising and delivering courses; and 4) liaison and networking, which involved formal and informal meetings about CPD and/or workforce issues within the deanery and with other NHS organisations. The Department of Health also provided funding to support RRAs to liaise and network with one another. Twice yearly RRA meetings provided opportunity for the RRAs to share their experiences of the new role and were structured to include an educational component. These meetings were also used to disseminate interim findings from the evaluation study.

Notably, not all RRAs engaged in all four activities. A key finding was that the nature of the role varied between deaneries. Specifically, RRAs had responsibility to ensure adequate provision of Getting Back to Practice courses for dentists returning from a career break. However, prior to the inception of the Retaining and Returning Advisory Service, the provision of these courses was not uniform across deaneries: thus some RRAs were very active in organising and running new courses, while others linked with existing ones. Differences between deaneries substantially affected the time committed to course organisation. What did not vary, however, was that supporting individuals on a one-to-one basis was the central part of the RRA role.

\section{Service uptake}

To attract dentists to the new service, all RRAs were actively engaged in promoting their role to potential users. This involved mail-outs to dentists already registered on KITS as well as to dentists who had informed the Dental Practice Board of their intention to terminate their contract prior to normal retirement age (ie dentists leaving their practice).

RRAs also networked at local dentistry meetings and delivered short presentations at courses, training events and conferences. Groups targeted included: undergraduates, vocational dental practitioners, practising dentists attending meetings and courses, as well as key personnel (eg Dental Practice Advisers, Dental Tutors, Dental Service Clinical Directors in Primary Care Trusts, Vocational Trainers, Consultants in Dental Public Health).

However, RRAs recognised that strategies to attract users to the new service mainly targeted those already on a career break. Those planning a break or thinking about leaving were 
(understandably) less 'visible' and proved much harder to reach. This was substantiated in the profile of service users.

Valid numbers for responses on the record forms highlight that most contacts were women (75\% - 151/203), over threequarters were dentists (85\% - 178/209) and most were experienced practitioners ie qualified over 10 years ago (82\% - 115/140). Relatively fewer hygienists and therapists were represented in the RRA contacts (12\% - 25/209) as many RRAs actively referred these to the DCP RRAs. Most users were on a career break when they first had contact with the RRA (73\% - 151/208), rather than planning a break (4\% - 9/208), or wanting support for a change in their current role $(6 \%$ - 12/208). The main reasons for career breaks were: childcare/family issues; pursuit of a new career outside dentistry; and overseas travel. This profile of users was corroborated by the RRA interview data.

RRAs also identified their contact with much smaller numbers of users who demonstrated (often, overlapping) characteristics of:

- Ill-health problems

- Poor performance or disciplinary issues

- Inability to cope/dissatisfaction with dentistry

- Dentists seeking VT equivalence

- Dentists, therapists or hygienists wanting to change role or increase hours

- Dentists on a career break and not eligible for KITS (eg had retired and were too old, not registered with the GDC) or not aware of KITS

- Overseas-trained or refugee dentists.

These relatively fewer numbers of individuals presented complex issues and support needs. RRAs talked extensively in interview about the time commitment involved in advising these often challenging cases.

Other users were those who had recently returned from a career break, and with whom the RRA continued to maintain contact. There was consensus that few RRAs had more than one or two users that were planning a break, for example a childcare break.

\section{Support provided}

The support provided by RRAs was both face-to-face and by telephone. Records demonstrate that most contacts were for about 45 minutes, and most individuals were followed-up at least once. Support was typically in one or more of three areas: general support, including planning CPD; specific information about returning to practice (eg job applications, changes in NHS guidelines, clinical guidelines); and specific advice about changing posts or role. Advice covered a range of specific enquiries eg VT equivalence, the International Qualifying Examination (IQE), information for therapists returning to the extended duties and different dental services (eg salaried).

In interview, all RRAs mentioned their role in promoting CPD activity - eg advising about GDC Lifelong learning requirements, helping in analysis of learning needs or even booking places on courses or putting names on mailing lists. Indeed, many RRAs used the first face-to-face meeting to facilitate the completion of a Personal Development Plan (PDP).

In supporting return to work, RRA activity included: informal networks for those on a career break; identification of supportive practices and opportunities for work shadowing; targeted basic clinical update sessions/core courses; ongoing support after update courses and/or return to practice; and practical help with curriculum vitae and job applications.

RRAs also provided encouragement and aimed to build confidence. All RRAs cited lack of confidence as a barrier to returning to practice, particularly those whose inability to cope or poor performance were the reasons they had ceased clinical practice. Several RRAs ( $\mathrm{n}=5$ ) mentioned pastoral support ie listening, reassuring and encouraging confidence - characterised by some as 'mentoring'.

Users revisited these themes in their feedback.

\section{User feedback}

Eighty-two user questionnaires were returned. Only users who had completed their contact with the Retaining and Returning Advisory Service were issued a questionnaire. RRAs were prompted to record and code the distribution of a questionnaire on the standardised record form completed for each one-to-one contact. During the 12-month monitoring period, 129 were sent out and with
82 returns, the response rate was $64 \%$. Three-quarters of returns were from women $(n=61)$ and $82 \%(n=67)$ were dentists, with remainder from hygienists or therapists. The majority (78\% - 64/82) had qualified more than 10 years ago. This is a good reflection of the profile of users identified from the record forms.

The questionnaire included nine statements about the Retaining and Returning Advisory Service to which users responded on a six-point scale. The results are summarised in Table 1; for positive statements the percentage of users rating 5 or 6 on the six-point scale (strongly/agreed) is shown, and for negative statements, the proportion of users rating 1 or 2 (strongly/disagreed) is presented.

Taken together, these responses represent a very positive impression of the Retaining and Returning Advisory Service. These users clearly had a very constructive experience: they considered the service was relevant/essential for them (93\%), had gained the information they needed (91\%), thought the RRA responded quickly (89\%), that the RRA had given them the time they needed $(86 \%)$, they planned to keep in touch (78\%), and would recommend the service to others $(88 \%)$. The one statement that falls outside the general pattern of responses is the one reading 'The RRA helped me to make decisions about my professional career'. Although only 38\% strongly agreed, a further $37 \%$ gave a rating of 4 (weaker agreement).

In an open question, users were invited to identify what had been the most useful aspect of their contact with the RRA. Seventy-eight people identified 114 aspects. These are summarised in Table 2.

These responses reinforced earlier findings. These users valued general information about CPD, specific support in planning $\mathrm{CPD}$ and motivating them to return to work. Comments included: 'Discussing my future with a fellow professional who has been in practice' and 'Someone to talk to who listened and gave me confidence in myself'. Specific support in relation to job seeking was also frequently identified: 'Advice on what work is available out there'.

The 10 case studies were a clear endorsement of the Retaining and Returning Advisory Service. Those interviewed were mainly users who had 
been out of practice and returned back to work. They included five female dentists, two male dentists, two female therapists and one female hygienist. The length of career break varied from a few months to 18 years. Reasons for the break also varied though commonly for the women in the case studies, the reasons related to childcare. Others included early retirement because of disillusionment with dentistry, and one was an overseastrained assistant dentist seeking vocational training equivalence to pursue work as an associate.

The case studies highlighted three recurring themes: the value of (i) joining KITS; (ii) going on an update course; and (iii) the support of the RRA. KITS had provided a supportive framework and Getting Back to Practice courses, particularly the hands-on elements, were seen by some as a prerequisite to returning to work. The encouragement and advice of the RRAs was seen as vital: 's/he made me feel it was possible ... made me think I could do it'. The RRAs were perceived to have local knowledge and contacts and had ensured a return to work which in some cases was sooner than initially thought. However, the interviews also reiterated the difficulties in returning to dentistry and the barrier presented by lack of confidence.

\section{RRA reflections of the role}

RRAs considered that one-to-one support and mentoring for those on KITS was at the heart of the role. For some, course organisation had also entailed a considerable time commitment.

There was agreement that the service had strengthened the existing KITS framework. By contacting KITS members within their own deanery they were able to provide educational advice and support for dentists planning to return. All RRAs concluded that their focus throughout the first 12 months had been on the 'returners'. Many suggested that there should be an increased emphasis on the retaining aspect of the initiative, with a shift 'to ensure support is there for those already in practice'.

One way in which RRAs suggested reaching those in the profession in need of support was to develop their role in reaching poorly performing dentists. Making links with workforce planners, Primary Care Trusts, Dental Practice Advisers, Deans, Consultants in Dental

\begin{tabular}{|c|c|c|}
\hline Positive statements & $\begin{array}{l}\text { Strongly agreed } \\
(5,6) \\
n(\%)\end{array}$ & Valid number \\
\hline This kind of service is essential for people like me & $75(93 \%)$ & 81 \\
\hline The RRA gave me, or directed me to the information I need & $74(91 \%)$ & 81 \\
\hline I will recommend the service to others & $72(88 \%)$ & 82 \\
\hline The RRA gave me the time I needed & $67(86 \%)$ & 78 \\
\hline I plan to keep in touch with the RRA & $64(78 \%)$ & 82 \\
\hline The RRA helped me to make decisions about my professional career & $30(38 \%)$ & 78 \\
\hline Negative statements & $\begin{array}{l}\text { Strongly disagreed } \\
(1,2) \\
n(\%)\end{array}$ & Valid number \\
\hline $\begin{array}{l}\text { I am less confident about my professional future after contact with } \\
\text { the RRA }\end{array}$ & $73(91 \%)$ & 80 \\
\hline The RRA was slow in responding to my enquiry(ies) & $70(89 \%)$ & 79 \\
\hline I was wary of discussing my concerns with the RRA & $68(83 \%)$ & 82 \\
\hline
\end{tabular}

Table 2 Most useful aspects of the RRA contact: user questionnaires

\begin{tabular}{|l|l|}
\hline Most useful aspects & Number of responses \\
\hline Support in planning/undertaking CPD & 56 \\
\hline Accessing materials, information on courses & 18 \\
\hline Making plans, including PDPs & 14 \\
\hline General discussion about CPD & 12 \\
\hline Specific contact details & 6 \\
\hline Information about requirements (incl. CPD and VT equivalence) & 6 \\
\hline Offered encouragement/motivation & 38 \\
\hline Increased confidence, reassurance, encouragement, motivation & 18 \\
\hline Sharing experiences, friendliness of RRA & 20 \\
\hline Careers advice/job information & 15 \\
\hline Support in returning to work & 11 \\
\hline Information about possible jobs, support in applying for jobs & 4 \\
\hline Other & 5 \\
\hline Total & 114 \\
\hline
\end{tabular}

Public Health, Local Dental Committees with a specific remit for poor performance was suggested.

There was consensus that deaneries had integrated RRAs into their wider activities and that one RRA was required for each deanery. Several RRAs emphasised the need for more time to the role than the two sessions per week - principally because of the demands of course provision, the particular pressure of high KITS numbers in some deaneries, the greater 
number of dentists covered by specific RRAs, geographical distances and the diverse range of presenting issues.

\section{DISCUSSION}

The findings demonstrate a clear need for this type of support and advisory service. Within their first year in post, RRAs had provided educational, practical and pastoral support for a range of dentists, which was welcomed by users. The case studies reiterate the difficulties experienced in returning to work highlighted by the Better opportunities for women report ${ }^{5,6}$ but also the considerable value in providing tailored support to facilitate return to practice.

The joint launch of the Retaining and Returning Advisory Service and the revised KITS funding created a comprehensive package of support for those planning a break or already taking a break from dentistry. Extra funding for KITS was welcomed, and registration on KITS increased in the evaluation period. With national Department of Health funding for KITS now in abeyance and the possibility to develop provision at the local level (eg PCTs, SHAs or deanery), reflection on this study's findings is timely.

However, the findings need to be understood within the limitations and confines of this study. It is worthy of reiteration that the evaluation of this service was conducted within its first 12 months and so outcomes in terms of numbers retained and returning to the profession is not appropriate here. Even in the longerterm the use of such numbers would be challenging. One reason for this is that a causal relationship between the numbers retained or returning to the workforce and use of the Retaining and Returning Advisory Service could only cautiously be drawn; other factors are likely to affect this issue, such as contractual changes, remuneration, and opportunity for flexible working arrangements. A second reason relates to the complexity of tracking workforce movement in the general dental service. At the time of the study, data sourced from the Dental Practice Board (DPB) sought to explore the number of dentists taking a break from the dental service. This exercise highlighted the considerable movement and difficulty in distinguishing between different types of 'leavers' ie those who were terminating their contract with the DPB and leaving the profession without intending to return, and those taking a career break. Thus, the RRAs' strategy of approaching those on KITS was both practical and well-targeted, since those on the KITS register have already identified their intention to maintain contact with the profession.

Despite the challenges of readily available numbers retained or returning to the profession, the triangulation of data collection methods, data sources (users, and RRAs), and the 12-month longitudinal aspect of the design add rigour to the conclusions that can be drawn from this study. ${ }^{12,13}$ In the spirit of formative evaluation, the study suggests the value in reflecting upon the roles and responsibilities of the RRA. The evaluation concluded that there was great potential for an extended RRA role, certainly within some deaneries, and this would necessitate additional training, extra sessions and/or would need additional personnel to support these activities.

Since fieldwork for this study was completed, the Retaining and Returning Advisory Service has continued across postgraduate dental deaneries in England, but funded locally from mainstream deanery budgets instead of centrally from the Department of Health. For example, in the West Midlands the RRA role has been extended to support other workforce and educational initiatives, such as providing additional support for overseas-trained dentists. The impact of these devolved funding arrangements merits further exploration.

\section{CONCLUSION}

In its first year, the Retaining and Returning Advisory Service provided support to a potentially vulnerable group of dentists. The combination of professional and personal support, access to courses, and the opportunities afforded by KITS membership was highly valued by users. The individual RRAs should be congratulated for the commitment they have shown to developing this role in ever changing circumstances.

The study concluded that the Retaining and Returning Advisory Service should be consolidated, and there was scope for further development.

The project team is grateful for the financial support of the Dental Division of the Department of Health (England) and the advice and encouragement from Dame Margaret Seward, former Chief Dental Officer (England). The views and opinions expressed are the authors' and do not necessarily reflect those of the Department of Health. Our thanks are also extended to the Returning and Retaining Advisers and the dentists, therapists and hygienists who gave time to the study.

1. Department of Health. NHS dentistry: delivering change - a report by the Chief Dental Office (England) July 2004. London: Department of Health, 2004.

2. NHS Careers. Returning to the NHS. Available at www.nhscareers.nhs.uk/nhs/comingback.html. [Accessed 23/07/06]

3. Thornett A, Chambers R, Baker M. Keeping doctors in general practice. Br Med J 2003; 327: 145-146.

4. Muller E. Returning to general practice. Br Med J 2003; 326: s37-s38.

5. Hastie A. The general practitioner retainer scheme. Br Med J Careers; 326: 2-3.

6. Seward M. Better opportunities for women dentists - a review of the contribution of women dentists to the workforce. London: Department of Health, 2001. Available at http://www.dh.gov.uk/PublicationsAndStatistics/Publications/PublicationsPolicyAndGuidance. [Accessed 12/10/06]

7. Murray JJ. Better opportunities for women dentists: a review of the contribution of women dentists to the workforce Br Dent J 2002; 192: 191-196.

8. General Dental Council. Lifelong learning. London: General Dental Council, 2000.

9. NHS Careers. Taking a break from dentistry? Keeping your options open with KITS. Available at: www.nhscareers.nhs.uk/careers/dentists/OptionsOpen.pdf. [Accessed 23/07/06]

10. Firmstone V, Bullock A, Bedward J et al. An evaluation of the effectiveness of the Retaining and Returning Initiative in England. Birmingham: University of Birmingham, 2004.

11. Coffey A, Atkinson P. Making sense of qualitative data. London: Sage, 1996.

12. Denzin N K. The research act in sociology: a theoretical introduction to sociological methods. Chicago: Aldine, 1970.

13. Miles M B, Huberman A M. Qualitative Data Analysis: an expanded sourcebook. 2nd ed. London: Sage, 1994. 